\title{
Using a pilot study to evaluate an assessment strategy for a future Stage III efficacy trial: Example from tuned lighting demonstration
}

Ellen McCreedy ( $\nabla$ ellen_mccreedy@brown.edu )

Brown University School of Public Health

Caroline Mills

Brown University School of Public Health

Rosa Baier

Center for Longterm Care Quality and Innovation, Brown University

Eunice Noell-Waggoner

Center for Design of an Aging Society

Naomi Miller

Pacific Northwest National Laboratory

Scott Stringer

ACC Care Center

Rebecca Uth

Brown University School of Public Health

David Gifford

American Health Care Association

Terrie Wetle

Brown University School of Public Health

\section{Research Article}

Keywords: pilot study, feasibility study, nursing home, NIH stage model

Posted Date: April 16th, 2021

DOI: https://doi.org/10.21203/rs.3.rs-426433/v1

License: (c) (i) This work is licensed under a Creative Commons Attribution 4.0 International License.

Read Full License 


\section{Abstract \\ Background}

Poor sleep among residents in nursing homes is common and associated with decreased function and falls. Tunable lighting which mimics both day and night exposure may improve sleep. In this pilot study, we evaluate an assessment strategy to determine the appropriate outcome measure for a future Stage III efficacy trial.

\section{Methods}

This pilot study uses a crossover design, in which three hallways were randomized to tunable LED or static lighting for two months (December 2018-January, 2019) and then switched to the other condition for two months (February-March, 2019). Residents who had been in the nursing home for at least 90 days were eligible. We measured sleep (primary) and agitation (secondary) outcomes using key informant interviews and available administrative data. We measured sleep by interviewing staff using the Sleep Disorders Inventory (SDI) and Minimum Data Set (MDS) resident assessments. We measured agitation by interviewing staff using the Cohen-Mansfield Agitation Inventory (CMAI) and MDS assessments. We used McNemar's test and Wilcoxon matched-pairs signed-ranks tests to compare within-person changes for all measures.

\section{Results}

62 residents, 35 of whom had dementia, had complete MDS and SDI data available. The average resident age was 90 and $77 \%$ were Asian. The percent of residents with any sleep disturbances was lower in the tuned vs. static lighting conditions based on MDS measure ( $4.8 \%$ tuned, $14.5 \%$ static, $p<.10$ ); no difference was observed using the SDI (33.9\% tuned, $37.1 \%$ static). Sleep disturbances were less frequent in the tuned vs. static lighting conditions for both the MDS and SDI measures $(p<.10)$. No significant differences were observed for agitated behaviors.

\section{Conclusions}

Results suggest that the available MDS sleep measure under detects disturbances compared to the gold standard staff interview. Efficacy trials should consider staff interview as primary study outcome. Sensitivity to change in the MDS-based sleep measure could be tested in Stage III trial to determine appropriateness for Stage IV, pragmatic trial.

\section{Key Messages}


1) Uncertainty regarding feasibility of assessment strategy; 2) Widely available administrative measures of sleep may not adequately capture outcomes; 3 ) Future efficacy trials should consider augmenting existing administrative data with validated staff interview measuers

\section{Background}

Approximately one in five nursing home $(\mathrm{NH})$ residents have insomnia ${ }^{1}$ and 60 percent experience other types of sleep disturbances. ${ }^{2}$ Poor sleep been associated with decreased Activities of Daily Living performance, ${ }^{3}$ increased falls, ${ }^{4-6}$ and even decreased survival. ${ }^{7-10}$ Disrupted sleep may also increase daytime agitation in residents with dementia. ${ }^{11,12}$ Medications used to improve sleep, such as anticholinergics, nonbenzodiazepines, and hypnotics, also increase the risk of injurious falls. Non-drug interventions, such as physical activity, light exposure, and mid-body therapies, provide an alternative for $\mathrm{NHs}$ to address the issue of disrupted sleep through behavioral or environmental changes. ${ }^{13}$

Tunable LED lighting mimics the color and intensity of natural light throughout the day and night and, thus, may restore natural circadian rhythms without the use of medications. There are only a few studies of the effects of ambient tunable LED lighting on sleep and daytime agitation in the NH setting. In one study, blue-enriched white lighting was installed in communal rooms resulting in increased daytime alertness. ${ }^{14}$ Another involved installing a dynamic lighting system in the $\mathrm{NH}$ common room, resulting in reduced agitation but inconclusive sleep impact. ${ }^{15}$ Limitations of the current literature on permanent light fixtures includes: incomplete definitions of lighting protocols; and the use of permanent fixtures only in common rooms, not inclusive of hallway or bedroom lighting.

The purpose of this pilot was to inform the design and implementation of a Stage III real-world efficacy randomized, controlled trial. ${ }^{16}$ In addition to documenting a best practice protocol for implementing tunable lighting in the $\mathrm{NH}$ setting ${ }^{17}$ and determining stakeholder acceptability, ${ }^{18}$ we wanted to use our pilot to determine the feasibility of our assessment strategy. ${ }^{19}$ Specifically, we wanted to compare measures of sleep and agitation obtained by interviewing a staff member who knows the resident well to available administrative data, to determine the most appropriate outcome measure. ${ }^{20}$

\section{Methods}

\section{Design \& Randomization}

This pilot used a cross-over design with two time periods: December 1, 2018-January 31, 2019 and February 1, 2019-March 31, 2019. The tunable lighting was installed in three hallways in a nursing home. Each hallway was randomized, using simple randomization (coin flip by RB), to receive the tuned lighting for one of the two time periods, and the static lighting for the other period. There was no blinding of nursing home staff or researchers.

\section{Sample \& Data}


There were two study samples of interest. The first included all residents who had been in the $\mathrm{NH}$ at least 90 of the last 100 days on November 1, 2018. The second sample comprised the subset of all eligible residents who had a dementia diagnosis on November 1, 2018.

There were two sources of study data. The first data source was resident care planning assessments that are conducted quarterly by $\mathrm{NH}$ staff using a nationally-standardized instrument, the Minimum Data Set (MDS) version 3.0. ${ }^{21,22}$ Eligible residents were required to have two comprehensive MDS assessments, one between November 1, 2018 and January 31, 2019 and one between February 1, 2019 and April 30, 2019.

The second data source was survey data collected on-site by two trained data collectors (EM and CM) with experience interviewing $\mathrm{NH}$ staff. ${ }^{23}$ We collected survey data at two time points: January 30 February 1, 2019 and March 27-29, 2019. We interviewed nighttime nursing staff members about recent sleep disturbances for all residents; daytime nursing staff was interviewed about recent agitated behaviors for residents with a dementia diagnosis only.

\section{Key Study Measures}

\section{Resident Characteristics}

All resident characteristics were defined using MDS version 3.0 data. Resident demographic characteristics included age, sex, and race. Resident diagnoses of interest included: Alzheimer's or other dementias; depression; anxiety; and bipolar disorder or schizophrenia. Resident medication use was defined as the number of days in the past week that the resident received antipsychotics, antianxietals, antidepressants, hypnotics, and opioids. Moderate or severe cognitive impairment was defined as a score of 3 or 4 on the Cognitive Function Scale. ${ }^{24}$ Resident physical dependencies were defined by requiring extensive or total assistance with: transferring; moving around the $\mathrm{NH}$; and eating. Pain in the last five days was based on resident self-report or staff reported pain symptoms.

\section{MDS-Based Sleep and Agitation Disturbance Measures}

Sleep disturbances are not formally measured in the MDS. However, residents are screened for sleeprelated symptoms of depression using the Patient Health Questionnaire-9 Item (PHQ-9), which asks how often in the past two weeks the resident has had "trouble falling asleep or staying asleep or sleeping too much." Responses included: never or 1 day (0); 2-6 days (1); 7-11 days (2); or 12-14 days (3). Responses are captured by interviewing the resident or asking staff when the resident is not able to be interviewed.

To measure agitation in the past week, we focused on four MDS items: physical behaviors directed toward others; verbal behaviors directed toward others; other behaviors not directed toward others; and rejection of needed evaluation or care. The frequency with which each behavior occurred in the past week was recorded as never (0), 1 to 3 days (1), 4-6 days (2), or daily (3). These four items were summed to create the Agitated and Reactive Behavior Scale. ${ }^{25}$ 


\section{Survey-Based Sleep and Agitation Disturbance Measures}

The two data collectors (EM and $\mathrm{CM}$ ) interviewed nighttime nursing staff who knew the residents well using the Sleep Disorders Inventory (SDI). ${ }^{26}$ The SDI assesses the frequency of the following behaviors in the past two weeks: difficulty falling asleep; getting up during the night; wandering, pacing or getting involved in inappropriate activities at night; waking up residents during the night; waking up and thinking it is morning; and getting up too early. The frequency of each behavior is recorded as: never, less than once per week (1), 1-2 times per week (2), several times per day but not every night (3), or every night (4). For each behavior, severity is also assessed as mild (1), moderate (2), or marked (3). Total SDI score is derived by summing the products of the frequency and severity ratings for each behavior.

To assess the frequency of agitated behaviors, the two data collectors (EM and CM) interviewed daytime nursing staff who knew the residents well using the Cohen-Mansfield Agitation Inventory (CMAI). ${ }^{27}$ The CMAI asks about 29 verbally- and physically agitated and aggressive behaviors, such as yelling, cursing, kicking, or pacing. Staff were asked how often each of these behaviors occurred in the past two weeks: not applicable (0), never (1), less than once a week (2), once or twice a week (3), several times a week (4), once or twice a day (5), several times a day (6), or several times an hour (7). The total CMAl score is derived by summing the reported frequencies for all behaviors.

\section{Analysis}

We used McNemar's test and Wilcoxon matched-pairs signed-ranks tests to compare tuned and static measures of agitation and sleep. These tests were chosen because of the small sample, repeated measurement, and the non-normal distribution of the data. All analyses were conducted using STATA, SE Version 16. This pilot study is not intended to be used to determine sample or effect sizes for future RCTs. ${ }^{19}$

\section{Results}

There were 68 residents with an eligible assessment in both time periods, 62 of whom had sleep survey data available for both time periods. Characteristics of these 62 residents are provided in Table 1. The average resident age was 89.8 (SD:7.6), 69\% were women, and 77\% were Asian. Residents experienced significant cognitive and physical impairment: over half had a dementia diagnosis and $39 \%$ had moderate or severe cognitive impairment; $81 \%$ require extensive or total staff support to transfer from a bed to a chair, $53 \%$ are unable to move around independently, and $23 \%$ require extensive or total staff support to eat. Nearly one-third of residents (29\%) were diagnosed with depression and almost a quarter $(23 \%)$ received an antidepressant in the past week. Residents were also likely to experience pain in the last five days (44\%) and 19\% received an opioid in the past week. Characteristics of the 35 residents with dementia were similar to the entire sample, except they had higher levels of moderate or severe cognitive impairment (54\%) and more depression (34\%). 
Table 1

Characteristics of Study Sample under Static Lighting Condition

\begin{tabular}{|c|c|c|c|c|}
\hline & \multicolumn{2}{|c|}{$\begin{array}{l}\text { All Eligible } \\
\text { Residents* } \\
(\mathrm{N}=62)\end{array}$} & \multicolumn{2}{|c|}{$\begin{array}{l}\text { Eligible Residents with } \\
\text { Dementia* } \\
(\mathrm{N}=35)\end{array}$} \\
\hline & $\mathbf{N}$ & $\%$ & $\mathbf{N}$ & $\%$ \\
\hline \multicolumn{5}{|l|}{ Demographics } \\
\hline Age, Mean (SD) & \multicolumn{2}{|c|}{$89.8(7.6)$} & \multicolumn{2}{|c|}{$89.6(8.5)$} \\
\hline Male & 19 & $(30.7)$ & 9 & $(25.7)$ \\
\hline Asian & 48 & $(77.4)$ & 24 & $(68.6)$ \\
\hline White & 9 & $(14.5)$ & 7 & $(20.0)$ \\
\hline Other race or ethnicity & 5 & $(8.1)$ & 4 & $(11.4)$ \\
\hline \multicolumn{5}{|l|}{ Cognitive Impairment } \\
\hline Alzheimer's or Related Dementia & 35 & $(56.5)$ & 35 & $(100.0)$ \\
\hline Moderate or Severe Impairment & 24 & $(38.7)$ & 19 & $(54.3)$ \\
\hline \multicolumn{5}{|l|}{ Physical Impairment } \\
\hline $\begin{array}{l}\text { Dependent on staff to transfer from bed to } \\
\text { chair }\end{array}$ & 50 & $(80.6)$ & 29 & $(82.9)$ \\
\hline $\begin{array}{l}\text { Dependent on staff to move around nursing } \\
\text { home }\end{array}$ & 33 & $(53.2)$ & 20 & $(57.1)$ \\
\hline Dependent on staff for eating & 14 & $(22.6)$ & 12 & $(34.3)$ \\
\hline \multicolumn{5}{|l|}{ Medications (Any use in the last 7 days) } \\
\hline Antipsychotics & 5 & $(8.1)$ & 5 & $(14.3)$ \\
\hline Antianxiety & 2 & (3.2) & 1 & $(2.9)$ \\
\hline Antidepressants & 14 & $(22.6)$ & 10 & $(28.6)$ \\
\hline Hypnotic & 1 & $(1.6)$ & 0 & $(0.0)$ \\
\hline Opioid & 12 & $(19.4)$ & 6 & $(17.1)$ \\
\hline \multicolumn{5}{|l|}{ Other Conditions \& Symptoms } \\
\hline Depression & 18 & $(29.0)$ & 12 & $(34.3)$ \\
\hline Anxiety & 13 & $(21.0)$ & 9 & $(25.7)$ \\
\hline Schizophrenia or Bipolar Disorder & 3 & $(4.8)$ & 3 & (8.6) \\
\hline
\end{tabular}




\begin{tabular}{|c|c|c|c|c|}
\hline & \multicolumn{2}{|c|}{$\begin{array}{l}\text { All Eligible } \\
\text { Residents* } \\
(\mathrm{N}=62)\end{array}$} & \multicolumn{2}{|c|}{$\begin{array}{l}\text { Eligible Residents with } \\
\text { Dementia* } \\
(\mathrm{N}=35)\end{array}$} \\
\hline Pain (last 5 days) & 27 & $(43.5)$ & 9 & $(25.7)$ \\
\hline
\end{tabular}


Table 2

Presence and Frequency of Sleep Disturbances and Agitated Behaviors under Static Lighting and Tuned Lighting Conditions - Comparison of Key Informant Interview and Administrative Data (causality not implied)

\begin{tabular}{|c|c|c|c|c|}
\hline & $\begin{array}{l}\text { Static } \\
\text { (All } \\
\text { Residents) }\end{array}$ & $\begin{array}{l}\text { Tuned } \\
\text { (All } \\
\text { Residents) }\end{array}$ & $\begin{array}{l}\text { Static } \\
\text { (Dementia } \\
\text { Only) }\end{array}$ & $\begin{array}{l}\text { Tuned } \\
\text { (Dementia } \\
\text { Only) }\end{array}$ \\
\hline & $n=62$ & $n=62$ & $\mathrm{n}=35$ & $\mathrm{n}=35$ \\
\hline $\begin{array}{l}\text { Any sleep disturbances in past two } \\
\text { weeks }\end{array}$ & $\mathbf{N}(\%)$ & $\mathbf{N}(\%)$ & $N(\%)$ & $N(\%)$ \\
\hline $\begin{array}{l}\text { Key Informant Interview } \\
\text { (Sleep Disturbance Inventory) }\end{array}$ & $23(37.1)$ & $21(33.9)$ & $16(45.7)$ & $13(37.1)$ \\
\hline $\begin{array}{l}\text { Administrative Data } \\
\text { (Minimum Data Set) } \ddagger\end{array}$ & $9(14.5)$ & $3(4.8)^{\star}$ & $3(8.6)$ & $1(2.9)$ \\
\hline $\begin{array}{l}\text { Frequency of sleep disturbances in past } \\
\text { two weeks }\end{array}$ & Mean (SD) & Mean (SD) & Mean (SD) & Mean (SD) \\
\hline $\begin{array}{l}\text { Key Informant Interview } \\
\text { (Sleep Disturbance Inventory) } \S\end{array}$ & $3.6(7.2)$ & $1.8(3.8) \dagger$ & $4.6(8.1)$ & $2.5(4.5) \dagger$ \\
\hline $\begin{array}{l}\text { Administrative Data } \\
\text { (Minimum Data Set) } \|\end{array}$ & $.15(.36)$ & $.06(.31) \dagger$ & $.09(.28)$ & $.03(.17)$ \\
\hline Any agitated behaviors in past week & $\mathrm{N}(\%)$ & $\mathrm{N}(\%)$ & $\mathrm{N}(\%)$ & $N(\%)$ \\
\hline $\begin{array}{l}\text { Key Informant Interview } \\
\text { (Cohen Mansfield Agitation Inventory) }\end{array}$ & $\begin{array}{l}\text { Not } \\
\text { collected }\end{array}$ & $\begin{array}{l}\text { Not } \\
\text { collected }\end{array}$ & $17(48.6)$ & $21(60.0)$ \\
\hline $\begin{array}{l}\text { Administrative Data } \\
\text { (Minimum Data Set) } * \star\end{array}$ & $13(21.0)$ & $14(22.6)$ & $10(28.6)$ & $12(34.3)$ \\
\hline $\begin{array}{l}\text { Frequency of agitated behaviors in past } \\
\text { week }\end{array}$ & Mean (SD) & Mean (SD) & Mean (SD) & Mean (SD) \\
\hline $\begin{array}{l}\text { Key Informant Interview } \\
\text { (Cohen Mansfield Agitation Inventory) }\end{array}$ & $\begin{array}{l}\text { Not } \\
\text { collected }\end{array}$ & $\begin{array}{l}\text { Not } \\
\text { collected }\end{array}$ & $36.9(9.2)$ & $36.2(7.7)$ \\
\hline $\begin{array}{l}\text { Administrative Data } \\
\text { (Minimum Data Set) } \dagger\end{array}$ & $.39(.88)$ & $.37(.79)$ & $.49(.89)$ & $.57(.95)$ \\
\hline \multicolumn{5}{|l|}{${ }^{*} \mathrm{p}$-value $<.10$, McNemar's test } \\
\hline$e<.10, \mathrm{~V}$ & & & & \\
\hline
\end{tabular}




\begin{tabular}{|c|c|c|c|}
\hline Static & Tuned & Static & Tuned \\
\hline $\begin{array}{l}\text { (All } \\
\text { Residents) }\end{array}$ & $\begin{array}{l}\text { (All } \\
\text { Residents) }\end{array}$ & $\begin{array}{l}\text { (Dementia } \\
\text { Only) }\end{array}$ & $\begin{array}{l}\text { (Dementia } \\
\text { Only) }\end{array}$ \\
\hline$n=62$ & $n=62$ & $n=35$ & $n=35$ \\
\hline
\end{tabular}

‡ Item D0200C1="Over the past two weeks, have you had trouble falling asleep or sleeping too much?"

$\S$ Average of categorical response categories: $0=$ never, $1=$ less than once per week, $2=1-2$ times per week, 3 = several times per day but not every night, $4=$ every night

I| Average of categorical response categories: $0=$ never or 1 day, $1=2-6$ days, $2=7-11$ days, $3=12-$ 14

** Items E0200A-C, E0800 = physical behaviors directed toward others, verbal behaviors directed toward others, other behaviors not directed toward others, and rejection of needed evaluation or care

†Average of categorical response categories: $1=$ never; 2 : less than once a week, but still occurring, 3 $=$ once a week; $4=$ several times a week; $5=$ once or twice a day; $6=$ several times a day; $7=$ several times an hour

†Average of categorical response categories: 1 = behavior occurred 1 to 3 days; 2 = behavior occurred 4 to 6 days; 3 = behavior occurred daily

Sleep

Based on interviews with nighttime nursing staff who knew the resident well, there was no difference in the percent of residents with any sleep disturbances under the static and tuned lighting conditions (37\% vs $34 \%$ respectively). Based on the MDS sleep measure, nine of the 62 residents (15\%) had any sleep disturbances under the static lighting condition, compared to three of the 62 residents $(5 \%)$ under the tuned lighting condition $(\mathrm{p}<.10)$. Based on interviews, the frequency of sleep disturbances under the static lighting was 3.6 (SD:7.2) and under the tuned condition 1.8 (SD:3.8) $(\mathrm{p}<.10)$. Based on the MDS sleep measure, the frequency of sleep disturbances under the static lighting was .15 (SD:.36) and under the tuned condition .06 (SD:.31) $(p<.10)$. Among residents with dementia, only the frequency of sleep disturbances as measured by staff interview was statistically different between tuned and static groups [4.6 (SD:8.1) and 2.5 (SD:4.5) respectively, $\mathrm{p}<.10]$.

Agitation

Based on interviews with daytime nursing staff who knew the residents with dementia well, there was no statistical difference in the percent of residents with any agitation under the static and tuned lighting conditions ( $49 \%$ vs $60 \%$ respectively). Based on the MDS agitation measure, there was no statistical difference in the percent of residents with any agitation under the static and tuned lighting conditions ( $29 \%$ vs. $34 \%$ respectively). Based on interviews, there were no differences in the frequency of agitated behaviors under the static and tuned lighting conditions [36.9 (SD:9.2) and 36.2 (SD: 7.7) respectively]. 
Based on the MDS agitation measure, there were no differences in the frequency of agitated behaviors under the static and tuned lighting conditions [.49 (SD:.89) vs. .57 (SD:.95) respectively].

\section{Discussion}

These pilot results are important for researchers seeking to conduct real-world efficacy trials of nonpharmaceutical interventions to address sleep disturbances among NH residents. There is no validated sleep inventory embedded in the current version of the MDS; the MDS item used to assess presence and frequency of sleep disturbances is based on one item from the PHQ-9. The MDS version of the PHQ-9 has been shown to have good measurement ${ }^{28}$ and criterion validity, ${ }^{29}$ but the scale was not developed to measure sleep. Respondents may not report sleep disturbances that they believe are unrelated to depression, which may partially explain why only $15 \%$ of residents had any sleep disturbance reported in the MDS compared to $37 \%$ of the same residents based on staff interview data.

One limitation of this pilot was an incomplete alignment between the study window and the MDS assessments. For the full trial, we would like to be able to coordinate the staff interviews to occur during the same week as the regularly scheduled MDS assessments. Another limitation was the effect of language barriers on reporting of agitated behaviors. Many of the residents in this $\mathrm{NH}$ spoke Mandarin, Cantonese, or Japanese. A few CMAl items are dependent on staff and residents sharing a common language (e.g., questions asking whether residents are repeating the same questions / sentences over and over). Another barrier to administering the CMAl was time constraints. Day staff were required to be off the floor for 15 minutes per interview. Interviewing staff about resident sleep disturbances using the SDI was less burdensome because the interviews were five minutes each and they were conducted between midnight and 2 am.

\section{Conclusions}

Based on the results of this pilot, we recommend that sleep be measured by the gold standard SDI for the Stage III trial. By collecting the MDS and the SDI during the same week, the efficacy trial will help researchers to understand the relationship between these measures and the degree of sensitivity to change in the muted MDS measure. Using administrative data reduces costs and pragmatism of future trials, ${ }^{30}$ assuming symptoms are detected at comparable levels to the gold standard measures and the measures are similarly sensitive to change. ${ }^{31}$ Depending on budget, the addition of actigraphy may shed further light on sleep disturbances and highlight some of the biases in the existing, recall-based measures. $^{32}$

\section{Declarations}

Ethics approval: Because staff participated in the interviews in a professional capacity and did not provide personal information other than name and title, this analysis is not considered human subjects research or subject to Institutional Review Board approval. 
Consent for publication: not applicable

Availability of data and materials: The datasets used and/or analysed during the current study are available from the corresponding author on reasonable request.

Competing interests: The authors declare that they have no competing interests

Funding: This study was funded by the Jim H. McClung Lighting Research Foundation. The sponsor was not involved in the design, methods, subject recruitment, data collections, analysis and preparation of paper.

Author contributions: EM and CM analyzed and interpreted the data. EM, RB, and TW conceptualized and wrote the manuscript. ENW, NM, SS, RU, and DG provided critical edits to the manuscript.

Acknowledgements: Not applicable

\section{References}

1. Gindin J, Shochat T, Chetrit A, et al. Insomnia in long-term care facilities: a comparison of seven European countries and Israel: the Services and Health for Elderly in Long TERm care study. J Am Geriatr Soc. 2014;62:2033-9. DOI:10.1111/jgs.13099. 2014/10/31.

2. Martin JL, Webber AP, Alam T, et al. Daytime sleeping, sleep disturbance, and circadian rhythms in the nursing home. Am J Geriatr Psychiatry. 2006;14:121-9.

DOI:10.1097/01.JGP.0000192483.35555.a3. 2006/02/14.

3. Valenza MC, Cabrera-Martos I, Martin-Martin L, et al. Nursing homes: impact of sleep disturbances on functionality. Arch Gerontol Geriatr. 2013;56:432-6. DOI:10.1016/j.archger.2012.11.011. 2013/01/01.

4. Jiang Y, Xia Q, Wang J, et al. Insomnia, Benzodiazepine Use, and Falls among Residents in Long-term Care Facilities. Int J Environ Res Public Health 2019; 16 2019/11/27. DOI: 10.3390/ijerph16234623.

5. Ma T, Shi G, Zhu Y, et al. Sleep disturbances and risk of falls in an old Chinese population-Rugao Longevity and Ageing Study. Arch Gerontol Geriatr. 2017;73:8-14. . DOI:

10.1016/j.archger.2017.07.003.

6. Stone KL, Blackwell TL, Ancoli-Israel S, et al. Sleep disturbances and risk of falls in older communitydwelling men: the outcomes of Sleep Disorders in Older Men (MrOS Sleep) Study. J Am Geriatr Soc. 2014;62:299-305. . DOI: 10.1111/jgs.12649.

7. Dale MC, Burns A, Panter $L$, et al. Factors affecting survival of elderly nursing home residents. Int $J$ Geriatr Psychiatry 2001; 16: 70-76. 2001/02/17. DOI: 10.1002/1099-1166(200101)16:1<70::aidgps277>3.0.co;2-6.

8. Berry SD, Lee Y, Cai S, et al. Nonbenzodiazepine sleep medication use and hip fractures in nursing home residents. JAMA internal medicine. 2013;173:754-61. . DOI:

10.1001/jamainternmed.2013.3795.

Page $11 / 13$ 
9. Conn DK, Madan R. Use of sleep-promoting medications in nursing home residents: risks versus benefits. Drugs Aging. 2006;23:271-87. DOI:10.2165/00002512-200623040-00001. 2006/05/31.

10. Lai MM, Lin CC, Lin CC, et al. Long-term use of zolpidem increases the risk of major injury: a population-based cohort study. Mayo Clin Proc. 2014;89:589-94. . DOI:

10.1016/j.mayocp.2014.01.021.

11. Cohen-Mansfield J, Marx MS. The Relationship between Sleep Disturbances and Agitation in a Nursing Home. Journal of Aging Health. 1990;2:42-57. DOI:10.1177/089826439000200104.

12. Cohen-Mansfield J, Werner P, Freedman L. Sleep and agitation in agitated nursing home residents: an observational study. Sleep. 1995;18:674-80. 1995/10/01.

13. Shang B, Yin H, Jia Y, et al. Nonpharmacological interventions to improve sleep in nursing home residents: A systematic review. Geriatr Nurs. 2019;40:405-16. DOI:10.1016/j.gerinurse.2019.01.001. 2019/02/24.

14. Hopkins S, Morgan PL, Schlangen LJM, et al. Blue-Enriched Lighting for Older People Living in Care Homes: Effect on Activity, Actigraphic Sleep, Mood and Alertness. Curr Alzheimer Res. 2017;14:1053-62. . DOI: 10.2174/1567205014666170608091119.

15. Wahnschaffe A, Nowozin C, Haedel S, et al. Implementation of Dynamic Lighting in a Nursing Home: Impact on Agitation but not on Rest-Activity Patterns. Curr Alzheimer Res. 2017;14:1076-83. . DOI: $10.2174 / 1567205014666170608092411$.

16. Onken LS, Carroll KM, Shoham V, et al. Reenvisioning Clinical Science: Unifying the Discipline to Improve the Public Health. Clin Psychol Sci. 2014;2:22-34. DOI:10.1177/2167702613497932.

17. Miller N. Measuring Light Exposure and its Effects on Sleep and Behavior in Care Center Residents. PNNL; 2019.

18. T BRMEMNN-WESSGDURW. Impact of Tuned Lighting on Skilled Nursing Center Residents' Sleep. Seniors Housing \& Care Journal 2020; 28.

19. Leon AC, Davis LL, Kraemer HC. The role and interpretation of pilot studies in clinical research. J Psychiatr Res. 2011;45:626-9. DOI:10.1016/j.jpsychires.2010.10.008. 2010/10/28.

20. Lancaster GA, Dodd S, Williamson PR. Design and analysis of pilot studies: recommendations for good practice. Journal of evaluation in clinical practice. 2004;10:307-12. DOI:10.1111/j..2002.384.doc.x. 2004/06/11.

21. Saliba D, Jones M, Streim J, et al. Overview of significant changes in the Minimum Data Set for nursing homes version 3.0. J Am Med Dir Assoc. 2012;13:595-601. . DOI: 10.1016/j.jamda.2012.06.001.

22. Saliba D, Buchanan J. Making the investment count: revision of the Minimum Data Set for nursing homes, MDS 3.0. J Am Med Dir Assoc. 2012;13:602-10. DOI:10.1016/j.jamda.2012.06.002. 2012/07/17.

23. McCreedy EM, Yang X, Baier RR, et al. Measuring Effects of Nondrug Interventions on Behaviors: Music \& Memory Pilot Study. J Am Geriatr Soc. 2019;67:2134-8. . DOI: 10.1111/jgs.16069. 
24. Thomas KS, Dosa D, Wysocki A, et al. The Minimum Data Set 3.0 Cognitive Function Scale. Med Care. 2017;55:e68-72. . DOI: 10.1097/mlr.0000000000000334.

25. McCreedy E, Ogarek JA, Thomas KS, et al. The Minimum Data Set Agitated and Reactive Behavior Scale: Measuring Behaviors in Nursing Home Residents With Dementia. J Am Med Dir Assoc 2019; 20: 1548-52. . DOI: 10.1016/j.jamda.2019.08.030.

26. Tractenberg RE, Singer CM, Cummings JL, et al. The Sleep Disorders Inventory: an instrument for studies of sleep disturbance in persons with Alzheimer's disease. J Sleep Res. 2003;12:331-7. DOI:10.1046/j.0962-1105.2003.00374.x. 2003/11/25.

27. Finkel SI, Lyons JS, Anderson RL. Reliability and validity of the Cohen-Mansfield agitation inventory in institutionalized elderly. Int J Geriatr Psychiatry. 1992;7:487-90.

28. Bélanger E, Thomas KS, Jones RN, et al. Measurement validity of the Patient-Health Questionnaire-9 in US nursing home residents. Int J Geriatr Psychiatry. 2019;34:700-8. DOI:10.1002/gps.5074.

29. Saliba D, DiFilippo S, Edelen MO, et al. Testing the PHQ-9 interview and observational versions (PHQ9 OV) for MDS 3.0. J Am Med Dir Assoc. 2012;13:618-25. . DOl: 10.1016/j.jamda.2012.06.003.

30. Baier RR, Jutkowitz E, Mitchell SL, et al. Readiness assessment for pragmatic trials (RAPT): a model to assess the readiness of an intervention for testing in a pragmatic trial. BMC Med Res Methodol. 2019;19:156-6. DOI:10.1186/s12874-019-0794-9.

31. AHRQ Methods for Effective Health Care. In: Velentgas P, Dreyer NA, Nourjah P, et al, editors Developing a Protocol for Observational Comparative Effectiveness Research: A User's Guide. Rockville (MD): Agency for Healthcare Research and Quality (US)Copyright @ 2013, Agency for Healthcare Research and Quality., 2013.

32. Blytt KM, Bjorvatn $B$, Husebo B, et al. Clinically significant discrepancies between sleep problems assessed by standard clinical tools and actigraphy. BMC Geriatr. 2017;17:253.

\section{Supplementary Files}

This is a list of supplementary files associated with this preprint. Click to download.

- CONSORTpilotfeasibility.doc 